\title{
La bioética de Tristram Engelhardt: entre la contradicción y la postmodernidad
}

Raúl Madrid

\section{Resumen}

Se discute aquí cómo pueden formularse, desde el punto de vista bioético y social, juicios morales sin que éstos sean materiales. El fracaso de las grandes narraciones condiciona la fragmentación moral y el pluralismo de la postmodernidad. Al no existir, según Engelhardt, argumentos seculares suficientes para dirimir de manera final la querella entre las distintas visiones, éstas son, entre sí, extraños morales, y tienen que resolver sus diferencias por mutuo acuerdo, lo cual supone un desencanto con la razón, y un acto de desconfianza en su capacidad estructural para alcanzar la solución objetivamente más correcta de los problemas éticos y bioéticos. El trabajo es una discusión sobre el problema descrito en la obra de Engelhardt.

Palabras-clave: Ética. Ética basada en principios. Bioética.

\section{Resumo}

\section{A bioética de Tristram Engelhardt: entre a contradição e a pós-modernidade}

Discute-se aqui como podem ser formulados, do ponto de vista bioético e social, juízos morais sem que estes sejam materiais. $O$ fracasso das grandes narrações condiciona a fragmentação moral e o pluralismo da pósmodernidade. Segundo Engelhardt, na ausência de argumentos seculares suficientes para dirimir de maneira definitiva a controvérsia entre as diferentes visões, estas são, entre si, estranhos morais e têm que resolver suas diferenças de comum acordo, o que implica o desencanto com a razão, bem como um ato de desconfiança em sua capacidade estrutural para chegar à solução objetivamente mais correta dos problemas éticos e bioéticos. $\mathrm{O}$ trabalho é uma discussão sobre o problema descrito na obra de Engelhardt.

Palavras-chave: Ética. Ética baseada em princípios. Bioética.

\section{Abstract}

\section{The Tristram Hengelhardt's bioethics: between the contradiction and postmodernity}

The paper approaches how moral judgments can be formulated, from the bioethics and social perspective, without being material. The failure of extensive narrations entails moral fragmentation and pluralism in postmodernity. According to Engelhardt, since there are no secular arguments to settle the controversy between different moral visions, they become "moral strangers", and their differences must be settled by agreement, what implies a disenchantment of reason, and an act of distrust in its structural capacity to reach objective solutions to ethical and bioethical problems. This paper is a discussion on a topic described in Engelhardt's work. Keywords: Ethics. Principle-based ethics. Bioethics.

Doutor rmadrid@uc.cl - Pontificia Universidad Católica de Chile, Santiago, Chile. 


\section{Una bioética formal}

El problema que se aborda en las páginas que siguen no surge de la nada, sino que responde a ciertas estructuras que le sirven de marco, todas ellas funcionales al cuestionamiento de la noción de bien moral basado en categorías esencialistas. Este deslizamiento de la respuesta moral tiene una doble vertiente: la llustración y el postestructuralismo. La respuesta del autor que se aborda, como se intentará mostrar, es un diálogo con la primera, aunque incorpora elementos del segundo.

El punto de partida de Tristram Engelhardt para abordar la cuestión bioética es un supuesto aparentemente empírico: no existe una moral de contenidos que sea universal ${ }^{1}$. La "moral de contenido" o "material" es aquella que entrega orientación sobre lo que es bueno o malo, y propone conductas concretas al individuo, más allá de su obligación de no dañar a terceros. La moral procedimental, por el contrario, se refiere sólo la viabilidad formal o empírica de la norma, que intenta asegurar a través del establecimiento de instancias procesales. Una bioética que sirve de paradigma para otros casos concretos, necesariamente consistirá en una ética de carácter material.

Una "moral universal", a su vez, es aquella que se aplica a todos los hombres, en todos los lugares. La idea de universalidad de Engelhardt es contractualista: conseguir que los grupos humanos acepten un determinado contenido. La noción de una racionalidad capaz de formular bienes que, por la fuerza de la razón, puedan ser reconocidos por todos como tales, ha quedado - sostiene - superada con el fracaso moderno. Su apelación a la universalidad no tiene un contenido substantivo, es simplemente una búsqueda del acuerdo ${ }^{2}$, es decir, una ética y una bioética puramente formales. No se advierte en Engelhardt una formulación tan abstracta de esto como la que se encuentra en el postestructuralismo ${ }^{3}$ pero sí parece compartir el carácter fragmentario de las reglas, así como la imposibilidad de retrotraer esta situación al tiempo de las "grandes narraciones".

El punto de atención es el empeño moderno por fundar la moral: sus interlocutores son los ilustrados, no los escolásticos. Engelhardt fue educado, sin embargo, en la religión católica, que abandonó para ingresar en la Ortodoxa ${ }^{4}$. Su discusión con los modernos, y no con las teorías iusnaturalistas, hace pensar que su formación intelectual estuvo más vinculada con las posiciones contractualistas y liberales que con los autores del realismo clásico, como Santo
Tomás de Aquino y la Escuela Española del Derecho Natural.

Engelhardt estima que, una vez que comienza a debilitarse históricamente la síntesis cristiana, el impulso moderno no busca trastocar el sentido de la ética clásica, sino más bien garantizar la esencia de la autoridad moral en un mundo en el que la Revelación perdía fuerza cultural, a partir de los acontecimientos históricos, y como consecuencia de los paradigmas filosóficos que dominaban el ambiente intelectual de la época ${ }^{5}$. Por esto afirma que la redistribución de los intereses culturales en torno a la salud y a la postergación de la muerte están relacionadas con el fundamento del pensamiento moderno que surgió con el Renacimiento y la Reforma, y que rompe la unidad religiosa del Cristianismo Occidental ${ }^{6}$.

La visión cristiana tradicional del mundo tuvo que enfrentarse a un fanatismo religioso dividido en numerosas religiones $\mathrm{y}$ a las atracciones de un humanismo inmanente. El creciente interés por los studia humanitatis habría desbancado, de ese modo, a los studia divinitatis. En palabras de Macintyre, pertenece a la esencia de la razón el postular principios que son universales, categóricos e internamente consistentes, y por tanto, la moral racional postulará principios que estén en condiciones ser mantenidos por todo hombre, independientes de circunstancias y condiciones, que puedan ser obedecidos invariablemente por cualquier agente racional, en cualquier ocasión ${ }^{7}$.

El resultado, como es sabido, fue más bien adverso a este ideal. El vacío dejado por la pérdida de la unidad en la fe y la razón de los pensadores católicos no fue llenado por un programa secular de racionalidad moral que concitara el acuerdo de un mundo crecientemente más amplio y diverso, sino que produjo la situación contraria: si la unidad en el pensamiento sobre la vida buena iba a alcanzarse a través de la filosofía, la supresión del canon católico trajo la multiplicación de filosofías opuestas, también en el ámbito moral. Esto, según Engelhardt, es justamente el elemento que definirá la postmodernidad, aun cuando ello no se hizo observable sino hasta bien entrado el siglo XX: más que unidad en el Espíritu, había disidencia y discordia; más que una armonía de las convicciones, se producían disputas en la diversidad ${ }^{8}$. Su tesis es que, si bien el despliegue y consolidación de esta "nueva sensibilidad" es fruto de fuerzas históricas recientes, en realidad dicha diversidad había estado probablemente siempre presente, aunque de manera oculta, en la textura misma de la sociedad. Por eso afirma que la 
diversidad moral nos acompaña desde los primeros registros de la historia ${ }^{9}$.

La causa de esta circunstancia no es, para el autor, una cierta determinación interna del espíritu humano, de las sociedades o de la historia como podría encontrarse en otros autores igualmente contemporáneos (Derrida, por ejemplo) sino simplemente el grado de complejidad y el tamaño de las comunidades en que tal cosa se produce: para modelar una sociedad que no sea pluralista, casi seguramente habría que fijarse en una sociedad de escala muy reducida, probablemente que no exceda el ámbito de una ciudad-Estado griega...hay que recordar que la visión de la polis de Aristóteles, que tanta influencia tuvo en Occidente e indirectamente en el resto del mundo, era la de una pequeña ciudad que no recibía de buen grado a inmigrantes o a otros que pudiesen romper su unidad cultural ${ }^{10}$.

El hecho constitutivo de la época postmoderna es, por lo tanto, el hecho de la diversidad. No se trata de una diversidad que deba ser corregida, sino de una realidad que debe conseguir hacerse operativa. No hay que perder de vista la inspiración práctica del análisis de Engelhardt, cuya preocupación final es abordar correctamente problemas concretos de la bioética y de la medicina contemporánea; no proporcionar una explicación teórica a problemas filosóficos.

Mientras la modernidad todavía buscaba una tipo de moral material o dotada de contenido, la postmodernidad se conforma con el hecho de la mera diferencia: Engelhardt apunta que en la última década ha aumentado la aceptación de lo que hace cuarenta años hubiera sido impensable. Se ha desarrollado una amplia y bien articulada coalición de diferentes tendencias permisivas. Sin embargo, incluso en este punto la aparente coincidencia de pareceres pone en evidencia profundos desacuerdos, los que están a su vez entrelazados con otros desacuerdos ${ }^{11}$.

Dicho proyecto moderno - sostiene Engelhar$\mathrm{dt}$ - abarcaba además diversas comunidades religiosas o ideológicas, en la medida en que existía la esperanza de encontrar una concepción concreta de la justicia y de la acción moralmente correcta que expresara y tradujera las exigencias de la racionalidad y la humanidad. Cabe destacar la especial significación que tiene para el Profesor de Rice el concepto de "ideología", el cual entiende como una traducción secular de la religión, al consistir en la concatenación de ideas, imágenes, valores morales, supuestos metafísicos y epistemológicos que proporcionan a un conjunto de personas una concepción de la moralidad, de la justicia, de las estructuras sociales adecuadas y de la autoridad política legítima ${ }^{12}$.

Engelhardt sostiene que, en el período postmoderno, muchos autores e intelectuales parecen no darse cuenta de la instalación de la diferencia como elemento focal. De hecho, considera que la catástrofe fundamental de la cultura contemporánea es este fracaso de encontrar una moral secular canónica dotada de contenido ${ }^{13}$. Esta dicotomía parece responder a una actitud igualmente postmoderna del autor: una cosa es reconocer la existencia de la mentalidad diferencial propia del tiempo contemporáneo, y otra concluir que lo que se cree por fe (una moral universal y única) no es posible por medios naturales, de modo que lo natural se expresa por la diferencia; pero se sigue creyendo simultáneamente en el canon, de un modo ideal y abstracto, o bien personal y privado.

El también cae en la inconsecuencia, propia de una mentalidad basada exclusivamente en la diferencia, por la que llega a aceptar el argumento de la imposibilidad cultural de una ley moral de contenido universal, a lo que califica, finalmente, de sectaria (el contenido moral separa y censura ${ }^{14}$ ), y declarándose simultáneamente católico u ortodoxo. En el fondo, Engelhardt considera que toda concepción material de la moral es ideológica cuando pretende universalizarse ${ }^{15}$. En este punto, es interesante formular una comparación con Kant, quien se enfrenta en su momento a una problemática parecida, y ofrece una solución más armoniosa que la desarrollada por Engelhardt. Como es sabido, Kant considera que la religión no puede fundar la ética, por cuanto aquella tiene una base heterónoma, y la moral por el contrario debe basarse en una fuente autónoma. Esta diferencia explica y justifica, de un modo mucho más claro que en Engelhardt, el hecho de que dichas estructuras prescriptivas sean consideradas ámbitos distintos y separados. La mencionada distinción le permite al regiomontano evitar la incoherencia de pensar la ética de un modo diferente a lo que indica su religión, como le ocurre al autor de los Fundamentos de la bioética, que se ve forzado, precisamente por esta incoherencia, a formular la tesis de los "extraños morales" para referirse a la ética en la esfera pública.

Dado la realidad inevitable del pluralismo imperante en el mundo contemporáneo, y la limitada capacidad de la racionalidad para resolver controversias, la autoridad moral secular debe generarse en los acuerdos concretos de los individuos concretos, y limitarse a ellos ${ }^{16}$. Su proyecto consiste en el intento de proporcionar un marco por el que indivi- 
duos pertenecientes a distintas comunidades morales puedan considerarse vinculados por una estructura común; una especie de koiné glossa moral, que puede llegar a convertirse en una ética global ${ }^{17}$. Así pues, Engelhardt acepta los parámetros postmodernos en lo que a hechos se refiere - la fragmentación y la diversidad -, pero se inclina a proponer estructuras formales de acuerdo. Su intento no es el de un postmoderno; sino la reacción de un moderno que se declara creyente en una realidad trascendental que es en sí misma fundamento de toda moral, pero que termina cediendo a la configuración epocal de los estándares morales, aceptando, por así decirlo, las reglas del juego que proponen los enemigos de las tesis materiales.

\section{Los "extraños morales"}

Engelhardt advierte una condición de posibilidad para plantear la teoría de los "extraños morales" que preside su bioética: la necesidad de que exista una sociedad pluralista secular pacífica; donde los extraños tengan lugar y se encuentren. Denomina de este modo a las sociedades dispuestas a aceptar perspectivas morales diversas, de manera que sus habitantes están en condiciones de expresar sus puntos de vista sin temor a ser reprimidos ni censurados por ello ${ }^{10}$. Para poder operar, concluye, la convivencia (de la diversidad) debe tener un espacio, una instancia jurídica perfectamente acreditada y cierta. Engelhardt distingue entre comunidad y sociedad. El primer concepto se refiere a una asociación de individuos basada en una visión concreta, común a todos ellos, del bien; mientras que el segundo apunta a las asociaciones de individuos que no comparten dicha visión común del bien, pero que pueden tratar de alcanzar juntos un conjunto de objetivos importantes ${ }^{18}$.

Sostiene que es al interior de las comunidades concretas donde se producen las diversas posibilidades morales, y que dichos problemas morales deben contemplarse encarnados en la vida de personas reales ${ }^{19}$. Como no existen argumentos seculares suficientes, según él, para dirimir de manera terminante y objetiva la querella entre los distintos tipos de visiones (siempre que las alternativas, dice, respeten la libertad del inocente), dichas visiones son, entre sí, extraños morales. Los extraños morales tienen que resolver sus diferencias por mutuo acuerdo, ya que no comparten una moral de contenido, pero ello no significa que no puedan llegar a entenderse en absoluto: la primera estrategia de colaboración, cuando la verdad se convierte en in- tersubjetividad, y por lo tanto se hace múltiple, es reconocer los procedimientos para trabajar juntos sobre los desacuerdos morales y metafísicos. Esta estrategia ofrece a aquellos separados por diferentes visiones la posibilidad de obtener la autoridad no de Dios ni de la razón, sino del acuerdo, argumenta ${ }^{11}$. La extrañeza moral no exige que el otro sea incomprensiblemente diferente, sino sólo que se lo considere como alguien diferente en virtud de tener distintos compromisos morales o metafísicos ${ }^{20}$.

La supresión del canon en el concepto de extraños morales trae inmediatamente la contingencia de todo modelo ético y bioético. Engelhardt reconoce que, a pesar de este efecto, existe y permanece la aspiración de universalidad: sin embargo, también se aspira (a pesar de la fragmentación) a un sentido de secularidad que pueda abarcar diferentes ideologías y religiones y estar al alcance de todas las personas ${ }^{21}$. Lo que busca por lo tanto es una moral que consiga hacerse presente a pesar de la condición de extraños morales, y que pueda justificarse en diferentes comunidades, aunque éstas se encuentren fundadas en distintas tradiciones, ideologías o religiones.

De este modo, la propuesta de una ética universal y canónica, del tipo que sea (substantiva o procesal), se formula en razón de la existencia de los extraños morales; si todos fuéramos "amigos morales" no haría falta semejante empeño. La razón es, como dice Loewy, que incluso los extraños tienen relaciones entre ellos, y poseen obligaciones que se fundan en dichas relaciones ${ }^{22}$. Se trata de individuos pertenecientes a diferentes culturas y creencias, y que, por causa de ello, carecen de conexión social, excepto por la certeza de que cada uno quiere diseñar su vida del modo en que prefiera, según sus intereses personales ${ }^{2}$. Nada hay de común en los seres humanos, con excepción del empeño en seguir sus propios intereses y apetencias. Los individuos son los que autorizan o permiten las estructuras sociales que resultan autoritativas, y por ello es que, según el autor, la moral que vinculara a los "extraños morales" tendría o debiera tener un carácter inevitablemente libertario ${ }^{23}$. Ello - argumenta - es consecuencia de la imposibilidad de apoyarse en autoridades trascendentes para formular las premisas y principios morales, como Dios o la razón objetiva.

Este mecanismo de obtener la autoridad moral a través de la aquiescencia de los participantes de la comunidad es lo que Engelhardt denomina principio de autoridad moral: [este principio] subraya la circunstancia de que, cuando Dios no es escuchado por todos de la misma manera, cuando 
no todos pertenecen a una comunidad claramente definida y estrechamente unida y, ya que la razón fracasa en el intento de descubrir una moral canónica dotada de contenido, la autorización o autoridad moral justificada secularmente no se deriva de Dios, ni de la visión moral de una comunidad moral, sino de los individuos ${ }^{24}$.

Para hallar las bases de la cooperación entre esos individuos, los extraños morales deben buscar una estructura neutral (alguna estructura secular), en términos de que puedan descubrir qué tienen en común ${ }^{25}$. De este modo, cada uno dirige su vida de acuerdo a sus valores y bienes personales, sin que la moral secular vaya a interferir en la materialidad sus creencias, sino sólo en su modulación basada en el acuerdo ${ }^{26}$. Como todos los libertarios, Engelhardt no cree que se pueda ofrecer otra justificación de dicha moral, y menos, como ya se ha explicado, una fundamentación ${ }^{27}$. Por el contrario, de lo expuesto por el autor se deja ver que la única obligación universal que la razón nos puede ofrecer es aquella, única, de respetar estrictamente la libertad del otro.

Los extraños morales son necesarios para alcanzar la paz entre los hombres, al conseguir que las disputas y diferencias entre las personas ajenas no derive a un enfrentamiento, sino que puede llevarse a un determinado proceso de acuerdo que no vincule el ser material del problema. Como dice Parizau, Engelhardt va a abordar la cuestión de la ética desde un ángulo diferente, dejando de lado el contenido substancial de una ética universal, para interesarse por las condiciones de posibilidad de una ética que permita la cohabitación de perspectivas morales diferentes... Así la ética es un modo de resolver las controversias, en lugar de utilizar la fuerza y se define como un empeño de resolución de conflictos de manera no violenta ${ }^{28}$. Por esto es que sostiene que las diferencias entre las visiones morales son reales, y fundamentan concepciones sustancialmente diferentes, de tal modo que las controversias no se pueden resolver por medio de argumentos racionales lógicos, ni mediante la apelación a una autoridad moral reconocida por todos ${ }^{29}$.

En el fondo, la noción de extraños morales supone la afirmación de la incapacidad estructural de la razón humana para discernir los bienes morales en una dimensión fundamental o principal, quedando relegada exclusivamente a la comprensión y formulación de aspectos procedimentales. La íntima y radical determinación de lo que es un bien moral queda entregada por Engelhardt, a través de esta noción, a la conciencia de cada individuo, pero a una conciencia moral no exclusiva o específicamente cognitiva, sino a una en la que se entremezclan procesos relativos a la sensibilidad y la emotividad, lo que sí es propiamente postmoderno. Es lo que ocurre en su caso, a través de la religión ortodoxa, que tan exhaustivamente explica en la obra The Foundations of Christian Bioethics, ya citada. La aparente oposición que se produce entre este texto del año 2000, y The Foundations of Bioethics, de 1986, no es en realidad tal.

En la segunda obra Engelhardt expone la teoría de los extraños morales y los principios libertarios por los que busca la formulación de una ética secular no material, tal como se ha desarrollado aquí. En el primero trabajo, expone los fundamentos bioéticos de sus propios amgos morales: los cristianos ortodoxos. Engelhardt no busca proponerlos como base de una bioética general, aunque su particular visión del mundo y su religiosidad constituyen elemento determinante para poder comprender el sentido de su pensamiento, y del concepto de extraños morales ${ }^{30}$. Aun cuando parece inclinarse hacia la búsqueda de una racionalidad de base universal en sentido más bien moderno, su negativa a formularla, y la aceptación de las condiciones epocales como factor decisivo de su imposibilidad, lo convierte en un autor materialmente postestructuralista, si bien su análisis dista mucho de alcanzar los vericuetos teóricos de la llamada New French Theory.

Esto es, en mi opinión, también una ética que podríamos denominar desencantada o pesimista, pues la fuerte y poderosa dimensión religiosa del autor no consigue ilusionar al académico que argumenta, y no llega, aunque aparentemente quisiera, a concebir, en el tiempo presente la idea de un Dios-fundamento para justificar una ética y una bioética universal que fueran a la vez dotadas de contenido. Como ello no es aparentemente viable, de acuerdo con sus propios puntos de partida metodológicos, opta por formular una vía de unidad intersubjetiva, a partir de los puntos en común que pueden observarse en los extraños morales ${ }^{31}$.

Y no es sólo que el proyecto haya fracasado en establecer una moralidad canónica, o en recuperar una teoría general del debe ser de lo moral, sino que, una vez que la moral se ha vuelto secular, carece de la fuerza que era en general esperable en la cultura occidental cuando era reconocida, anclada y forzada por Dios. Estando, sin embargo, Dios ausente, cambia toda la apreciación de la moral; su significado metafísico, y la experiencia fenomenológica de ella y de la realidad ${ }^{32}$. El mismo Engelhardt agrega, en un texto reciente, que sin considerar la existencia de Dios y la inmortalidad del alma como premisas 
de la razón práctica, la moral se fragmenta, y deja de existir un fundamento vinculante para las obligaciones morales ${ }^{33}$, demostrando, una vez más, la importancia de la cuestión teológica en su reflexión.

\section{Consideraciones finales}

Como conclusión de lo expuesto, es posible entender la obra de Engelhardt como uno de los últimos esfuerzos - Harbermas - para restablecer la posibilidad de una ética global en un universo moral que comienza reconociendo y aceptando la diversidad y el multiculturalismo. Esta propuesta es intrínsecamente formal, y resulta contradictoria con las creencias per- sonales del autor, en tanto que éstas defienden implícitamente una ley natural material y universal. La posibilidad misma de esta contradicción, unida al uso que Engelhardt hace de la idea de la fragmentación para explicar la situación moral, muestran que la posición intelectual del autor oscila, o se ve integrada, por elementos postmodernos, que probablemente operan en él de modo inconsciente - a propósito de su concepción de la cultura -, junto con elementos contractualistas y desde luego comunitaristas. Esta variedad de presupuestos reafirma la idea de que no nos encontramos ante un filósofo abstracto de la acción moral, sino ante un académico que intenta resolver los problemas concretos de la bioética, campo en el cual su contribución ha sido muy relevante.

\section{Referências}

1. Engelhardt HT, Jr. Los fundamentos de la bioética. Madrid: Paidos; 1995. p. 57-8.

2. Engelhardt HT, Jr. The search for a global morality: bioethics, the culture wars and moral diversity. In: Engelhardt HT, Jr. editor. Global bioethics: the collapse of consensus. Salem: M\&M Scrivener Press; 2006. p. 18-49.

3. Derrida J. De la gramatología. Buenos Aires: Siglo XXI; 1971. p. 92.

4. Herman Tristram Engelhardt: how I became orthodox . Journey to Orthodoxy. [Internet]. 19 mar 2011 [acesso 28 jan 2001]. Disponível: http://journeytoorthodoxy.com/2011/03/19/hermantristram-engelhardt-how-i-became-orthodox/

5. Engelhardt HT, Jr. Op. cit.; 1995. p. 33.

6. Engelhardt HT, Jr. Salud, medicina y libertad: una evaluación crítica. In: Camps V, editor. Libertad y salud. Barcelona: Fundación Víctor Grífols i Lucas; 1999. p. 11-28. (Cuadernos de la Fundación Víctor Grífols i Lucas, v. 1)

7. MacIntyre A. Tras la virtud. Barcelona: Editorial Crítica; 1987. p. 67.

8. Engelhardt HT, Jr. Op. cit.; 1995. p. 34.

9. Engelhardt HT, Jr. Global bioethics: an introduction to the collapse of consensus. In: Engelhardt HT, Jr. editor. Global bioethics: the collapse of consensus. Salem: M\&M Scrivener Press; 2006. p. 15.

10. Engelhardt HT, Jr. Op. cit.; 1995. p. 35.

11. Engelhardt HT, Jr. Op. cit.; 1995. p. 16.

12. Engelhardt HT, Jr. Op. cit.; 1995. p. 460.

13. Engelhardt HT, Jr. Op. cit.; 1995. p. 15.

14. Engelhardt HT, Jr. Op. cit.; 1995. p. 45.

15. Engelhardt HT, Jr. Op. cit.; 1995. p. 44.

16. Cherry MJ, Iltis A. At the foundations of Christian Bioethics; or, why H. Tristram Engelhardt, Jr.'s Orthodox Christian bioethics is so very counter-cultural. In: Cherry MJ, Iltis A, editors. At the roots of Christian Bioethics: critical essays on the thought of H. Tristram Engelhardt Jr. Salem: M\&M Scrivener Press; 2010. p. 1-22.

17. Engelhardt $\mathrm{HT}$, Jr. The search for a global morality: Bioethics, the culture wars and moral diversity. In: Engelhardt HT, Jr. editor. Global bioethics: the collapse of consensus. Salem: M\&M Scrivener Press; 2006. p. 19.

18. Engelhardt HT, Jr. Op. cit.; 1995. p. 483.

19. Engelhardt HT, Jr. Op. cit.; 1995. p. 101.

20. Engelhardt HT, Jr. Op. cit.; 1995. p. 106.

21. Engelhardt HT, Jr. Op. cit.; 1995. p. 41.

22. Loewy EH. Moral strangers, moral acquaintance and moral friends: connectedness and its conditions. New York: State University of New York Press; 1997. p. 35.

23. Cherry MJ, Iltis A. Op. cit.; 2010. p. 6.

24. Engelhardt T. Op. cit.; 1995. p. 21.

25. Engelhardt HT, Jr. Global bioethics: an introduction to the collapse of consensus. Op. cit. p. 3.

26. Engelhardt HT, Jr. Political authority in the face of moral pluralism: further reflection on the nonfundamentalist state. Politeia. 2010;26(97): 92.

27. Loewy EH. Op. cit. p. 37.

28. Parizau MHHT. Engelhardt et l'ethique du discours. In: Hottois G, editor. Aux fondements d'une ethique contemporaine. París: Librairie Philosophique J. Vrin; 1993. p. 136.

29. Engelhardt HT, Jr. Op. cit.; 1995. p. 107. 
30. Delkeskamp-Hayes C. Morality in a postmodern, post-christian world: Engelhardt's diagnosis and therapy. In: Cherry MJ, Iltis A, editores. At the roots of Christian Bioethics: critical essays on the thought of H. Tristram Engelhardt Jr. Salem: M\&M Scrivener Press; 2010. p. 58-9.

31. Engelhardt HT, Jr. Op. cit.; 1995. p. 47.

32. Engelhardt HT, Jr. A skeptical reassesment of bioethics. In: Engelhardt HT, Jr. editor. Bioethics critically reconsidered. Dordrecht: Springer; 2012. p. 5.

33. Engelhardt HT, Jr. Moral obligation after the death of God: critical reflections on concerns from Immanuel Kant, G.W.F. Hegel, and Elizabeth Anscombe. Social Philosophy \& Policy. 2010;27(2):319.

Recebido: 3. 6.2014

Revisado: 4. 9.2014

Aprovado: 30.10 .2014 